\title{
The impact of affect on organizational justice perceptions: A test of the affect infusion model
}

\author{
Yina MaO*, Chi-Sum Wong**, Xiangnan Tao§ and Chunyan Jiang*
}

\begin{abstract}
How individuals form justice perceptions has been a fundamental question for organizational justice research. While most researchers have treated justice perceptions as a result of deliberate cognitive processes, a limited number of studies have examined the role of affect in forming justice perceptions. Using the affect infusion model, we investigate the predictive role of affect in forming justice perceptions and consider two moderating contextual factors: personal relevance and group context. Two experimental studies, with a student sample and an employee sample, were conducted. Results confirm that participants in positive affective states perceived higher distributive and procedural justice than those in negative affective states. Moreover, personal relevance moderates the relationships between affect and both distributive and procedural justice perceptions, and the relationship is enhanced as the level of personal relevance increases. The results also suggest that group context constrains the influence of an individual participant's affect on procedural justice.
\end{abstract}

Keywords: affect, affect infusion model, justice perceptions, personal relevance, group context

Received 10 December 2015. Accepted 18 August 2016

\section{INTRODUCTION}

$\mathrm{O}$ rganizational justice perceptions have been intensely studied as constructs that influence a variety of major organizational outcomes, such as organizational citizenship behavior, organizational commitment, job satisfaction, and turnover (for a review, see Colquitt, Conlon, Wesson, Porter, \& $\mathrm{Ng}$, 2001). While the consequences of justice perceptions have been thoroughly researched, there has been less work on the formation of justice perceptions. Although previous research has advanced our understanding of the process of justice perception formation, this process has been considered a deliberate cognitive response to objective reality, conducted in a strictly rational way (Barsky \& Kaplan, 2007). In other words, justice perception formation has been seen as a deliberative process that guides individuals' evaluations of organizational justice (De Cremer \& Van den Bos, 2007).

This view contradicts both our everyday subjective experience of injustice as 'hot' and emotionally laden, and the emerging recognition that affect and affective tendencies play a central role in workrelated social judgments (Barsky \& Kaplan, 2007), such as organizational justice. Cold cognitive

* Department of Human Resource Management, Nanjing University, Nanjing, Jiangsu Province, P. R. China

** Department of Management, The Chinese University of Hong Kong, Hong Kong, P. R. China

$\S$ Department of Marketing and Electronic Commerce, Nanjing University, Nanjing, Jiangsu Province, P. R. China Corresponding author: Xiangnan Tao; xntao@nju.edu.cn 
judgment is no longer sufficient to explain how individuals' justice perceptions are formed (Weiss $\&$ Cropanzano, 1996). Although it has not been commonly incorporated into research on justice perception, affect has become an important issue in organizational research. It has been shown to have an impact on constructs that are related to human judgment such as perception, attitudes, intergroup behavior, stereotyping, self-perception, and interview decisions (Schwarz \& Clore, 1983; Tanaka \& Takimoto, 1997; Brief \& Weiss, 2002). As the organization is an 'arena of emotions,' more attention should be paid in organizational research to the issue of affect.

Empirically, a few studies have investigated the relationships between affect and justice perceptions. For example, Mikula, Scherer, and Athenstaedt (1998) found that across 37 countries, people displayed affective reactions, such as anger, shame, and dissatisfaction, to injustice. However, these studies have assumed a justice-affect causal relationship such that affect is considered as a response to and consequence of justice events. The role of affect in forming organizational justice perceptions has received scant attention (Haidt, 2001; Barsky \& Kaplan, 2007). Even though both folk wisdom and literature have recognized that affect can color our judgments, scientific research in the justice field is a relatively recent development (Forgas \& Fiedler, 1996). Van den Bos (2003) intended to answer the question of whether people use their affect as input in forming justice perceptions, and under what conditions this is likely to happen. He found that in information-uncertain conditions, people's justice judgment will be strongly influenced by how they feel about the events they have encountered, even if such affective feelings have no logical relationship with the justice judgments they are making. Similarly, Hollensbe, Khazanchi, and Msterson (2008) observed that as employees' tenures lengthen, their use of affective states increases, because they start to trust their feelings about events. Additional empirical evidence comes from a meta-analysis study by Barsky and Kaplan (2007), which showed significant correlation between affective states and justice perceptions, but no causal direction was implied.

Based on the affect infusion model (AIM; Forgas, 1995), the current study systematically investigates whether affect influences organizational justice perceptions and specifies when, how, and why the influence of affect may or may not operate. It also models the complex, interactive relationship between affect and cognition (Forgas, 2002). This theory proposes processing strategies as the underlying mechanism. The AIM has been empirical supported in a variety of fields, such as cultural analysis (Keltner, Anderson, \& Gonzaga 2002), intergroup discrimination (Forgas \& Fiedler, 1996), attitudebehavior consistency in groups (Wellen, Hogg, \& Terry, 1998), service quality (Pugh, 2001), work motivation (Seo, Barrett, \& Bartunek, 2004), risk taking (Mittal \& Ross, 1998), and performance appraisal (Daus, 2001). Therefore, we believe that this model can also be applied to justice research to systematically explain the influence that affect exerts on forming organizational justice judgments.

In sum, the current study is aimed at understanding the role of affect in the formation of organizational justice perceptions. Using the AIM (Forgas, 1995), we examine the impact of affect on organizational justice perceptions, and the conditions under which affect influences individual's justice perceptions. Drawing on the AIM, we hypothesize that positive affect leads to higher justice perceptions and negative affect leads to lower justice perceptions. In addition, the AIM also proposes that the main effect of affect on organizational justice perceptions is subjective to some influences from judge features and situational features. We studied personal relevance (PR) and group context in the current study as manifestations of these two categories of moderators. Specifically, the more individuals care about the outcomes, procedures, and interpersonal treatment, the more their distributive, procedural, and interactional justice perceptions will be influenced by their affective states. Finally, we investigate the moderating role of group context on the relationship between affect and justice perceptions. We predict that in group context, the role of negative, but not positive affect will be inhibited from influencing justice perceptions.

The contributions of our study are fourfold. First, this research contributes to the justice literature by shifting the focus from cognitive factors to affective factors. It specifies and tests the role of affect in 
predicting individuals' justice perceptions using a solid theoretical foundation. Second, two conditions (i.e., PR and group context) are identified under which the influence of affect differs. Third, the experimental design supplements the dominant methodology of cross-sectional survey by providing strong evidence for the proposed causal relationships. Fourth, our data include a student sample and an employee sample, so the results can be cross-validated. This design enhances the external validity of the experimental findings by comparing the laboratory context with the real organizational context.

\section{LITERATURE REVIEW AND HYPOTHESES}

\section{Justice and affect}

After the groundbreaking work by Adams (1965), justice researchers began to focus on the fairness of outcomes, known as distributive justice. Distributive justice is perceived to be enhanced if the outcome is in accordance with explicit or implicit norms. The most extensively researched norm is equity. Other norms include equality, needs, reciprocity, and commitment (Deutsch, 1975; Leventhal, 1976). Another type of justice, concerned with the process of allocation, is procedural justice (Thibaut \& Walker, 1975). Leventhal and his colleagues argued that higher procedural fairness is likely to be achieved when procedures adhere to some criteria, such as consistency, lack of bias, correctability, representation, accuracy, and ethicality (Leventhal, 1980; Leventhal, Karuza, \& Fry, 1980). The most recent wave of justice research has focused on the enactment of procedures, referred to as interactional justice (Bies \& Moag, 1986). Two aspects of interactional justice have been identified, namely interpersonal justice and informational justice (Greenberg, 1993). The former represents the extent to which individuals are treated with respect and dignity, and the latter refers to the adequacy of the information and explanation provided by supervisors to justify the enactment of procedures. These two types of interactional justice were empirically examined as distinct constructs by Colquitt (2001). To be succinct, interactional justice will be referred to as the umbrella term to capture the domain represented by both interpersonal and informational justice perceptions hereafter.

An intensely studied construct in psychology, affect is used as a generic label to refer to both moods and emotions (Mayer, 1986). Moods are 'low-intensity, diffuse and relatively enduring affective states without a salient antecedent cause and therefore little cognitive content,' and emotions are 'more intense, short-lived and usually have a definite cause and clear cognitive content' (Forgas, 1992). In the current study, affect was treated as a whole because our theoretical framework applies to both moods and emotions. In addition, previous studies have shown that positive and negative affect are independent of each other and should be considered as conceptually distinct constructs (Diener \& Emmons, 1985; Isen \& Baron, 1991; George \& Brief, 1996), thus we have separated these two constructs, rather than regarding them as two poles of a single construct. Specifically speaking, positive and negative affect have different sets of consequences. It is found that distressing life events elicit more social response in individuals (Degoey, 2000) and negative events generally evoke stronger cognitive and emotional responses than neutral or positive events do (Taylor, 1991). Moreover, negative events also evoke more attempts at minimizing the emotional impact of these events. Other studies showed that positive affect seems to generate loose, creative, and heuristic processing strategies (Fiedler \& Forgas, 1988), whereas negative affect recruits more careful and substantive processing style (Forgas \& Bower, 1987). Positive and negative affect also differ in their length of effect that the influence of negative affect will be durable than positive affect. Venkatesh and Speier (1999) indicated that the effect of positive affect tends to be short term and the influence of negative affect tends to be long term.

It is not a new idea that justice is closely linked to affective factors. Adams (1965) found that underpayment led people to feel angry, while overpayment led people to feel guilty. In the same vein, relative deprivation theories suggest that when people are deprived of something to which they believe 
themselves to be entitled they feel discontent and stress (Folger, 1986). Mikula, Scherer, and Athenstaedt (1998) also found, in a study of 37 countries, that events seen as being unfair frequently produced anger. It is clear that justice (injustice) is associated with strong affective experiences and responses such as resentment, outrage, insulation, disgust, sadness, fear, and a desire for vengeance (Bies \& Tripp, 1996; Mikula, Scherer, \& Athenstaedt, 1998). In other words, previous research has established a causal sequence from justice perceptions to affective responses.

It is increasingly recognized that affect plays a significant role in influencing individuals' judgments. It has been suggested that the arousal of affect may occur before cognitive awareness, and under many circumstances affective responses at least emerge hand in hand with cognitive processes (Degoey, 2000). In other words, cognitive perspectives or rational models may not be the only type of processing used in the formation of organizational justice perceptions (Forgas, 1981; Weiss \& Cropanzano, 1996). Similarly, dual process theory assumes that under different contexts there are two different thinking processes: an implicit (automatic), unconscious process and an explicit (controlled), conscious process. In other words, the consciously rational process may be used in some situations, but in other contexts unconscious intuition may be very important. Further evidence can be found in the field of social psychology. On one hand, people are described as naive psychologists who invest their time and effort into deliberative and systematic thinking (Vaughan \& Hogg, 2005). On the other hand, they are sometimes cognitive misers (Fiske \& Taylor, 1991) who process information in an unsystematic way, for instance by relying on heuristics and instincts. Whether individuals are likely to act as naive psychologists or cognitive misers depends on the specific conditions and circumstances (Brewer, 1988).

Consistent with the foregoing argument, some empirical studies have provided evidence that affect may occur before any cognitive judgment on justice is made, and should always be considered as an important component of the process. For example, it has been suggested that individuals only perceive injustice when affective arousal occurs. In other words, when individuals encounter objectively unfair events, but are not affectively aroused, they do not perceive injustice (Scher \& Heise, 1993; De Cremer $\&$ Van den Bos, 2007). It seems that affect is a crucial and indispensible element in forming individuals' justice perceptions. Consistent with these arguments, we have treated affect as one of a variety of intuition inputs that individuals use to make judgments and we expect that affect can influence all individuals' justice perceptions, including distributive justice, procedural justice, interpersonal justice, and informational justice. Furthermore, we expect that the input of positive affect leads to higher justice perceptions and that inputs of negative affect leads to lower justice perceptions. Therefore, we propose the following affect-congruent effect:

Hypothesis 1: Positive affect is positively related to individuals' justice perceptions (distributive justice, procedural justice, interpersonal justice, and informational justice perceptions).

Hypothesis 2: Negative affect is negatively related to individuals' justice perceptions (distributive justice, procedural justice, interpersonal justice, and informational justice perceptions).

\begin{abstract}
AIM
The AIM attempts to describe how affect influences human's judgmental process and subsequent judgments. Affect infusion is defined as 'the process whereby affective loaded information exerts an influence on and becomes incorporated into the judgmental process, entering into the judge's deliberations and eventually coloring the judgmental outcome' (Forgas, 1995). Simply put, it refers to how affect influences individuals' perceptions. The most important aspect of AIM is that it not only argues that affect influences judgments, it also identifies situations under which that influence is greatest. According to AIM, there are four alternative judgmental strategies: direct access processing, motivated processing, heuristic processing, and substantive processing.
\end{abstract}


The direct access strategy is usually the simplest method of producing a judgment and individuals use this strategy when there is no need for constructive elaboration. It involves little or no constructive evaluation, and the strongly cued retrieval of an existing crystallized judgment is likely to be quite robust and resistant to affective distortion (Fiedler \& Forgas, 1988; Swann, 1992). This processing happens when the target is well known or familiar, has highly prototypical features and there are no strong cognitive, affective, or motivating forces requiring more elaborate processing. For example, Srull (1983, 1984) found that when making a judgment on a familiar product, customers were not be influenced by their affect. This is because facing familiar targets, individuals usually have a ready answer and response that does not need too much cognitive elaboration. Thus, there is little room for affect to influence judgment.

Similarly, motivated processing happens when there are strong and specific motivated pressures to achieve a particular judgmental outcome. It is guided by a prior motivated goal and also used to achieve mood maintenance and mood repair (Erber \& Erber, 1994). It is expected that when people have a strong motivation to control their mood, affect will have little influence on individuals' judgments. For example, Schwarz and Clore (1983) documented that individuals' life satisfaction and well-being were enhanced on sunny days and were lower on rainy days. However, this effect vanished when the individuals were reminded to be aware of the influence of weather. These individuals adopted a motivated processing strategy to control the influence of affect.

In contrast, the two other strategies, heuristic and substantive, are more open ended and constructive, allowing a greater influence of affect infusion. The heuristic processing is most likely to occur when the target is simpler or highly typical, the PR of the judgment is low, there are no specific motivated objectives, the judge has limited cognitive capacity, and the situation does not demand accuracy or detailed consideration. This is consistent with the principle of least effort (Chaiken, 1987), which proposes that people are inclined to choose the least costly solution. Consistent with this argument, some studies have offered evidence that affect is sometimes used heuristically to infer judgment. This is also known as the affect-as-information mechanism, through which affect leads people to substitute information while making their judgment. One variation of this processing occurs in information-uncertain conditions (Van den Bos, 2003). In such conditions, people may construct judgments by relying on how they feel about the events they have encountered and their perceptions may be strongly influenced by the affect information. This argument holds even when the affective states have no logical relationship with the justice judgments they are constructing, such as weather. Forgas and Moylan (1987) conducted a street survey by approaching individuals after they had watched happy or sad movies. Individuals were asked to give their opinions on various social issues, political figures, and their life satisfaction. The study found that participants who had seen a happy movie made significantly more positive judgments and had higher life satisfaction than those who had watched bad movies. Participants used the feelings arising from the movies as information even when making judgments on issues that had little PR.

Affect can play a major role in substantive processing through its selective influence on the kind of information used in making a judgment (Forgas, 1992). This happens most frequently when the target is complex or atypical and the judge has no specific motivation to pursue, has adequate cognitive capacity, and is motivated to be accurate, possibly because of explicit or implicit situational demands. The mechanism underlying this processing strategy is referred to as affect as priming. It has been demonstrated that affect can make certain aspects of the decision-making process more salient than others (Bower, 1991) and can influence the way people communicate and express the affective stimuli (Barsade, 2002). As previously mentioned, when the substantive processing strategy is adopted, affect influences individuals' judgment through a retrieval system. That is to say, positive things will be more likely to be recalled when the judges are in a good mood than when they are in a bad mood (Forgas, Bower, \& Krantz, 1984). In one study of personnel selection, interviewers who were in a good mood 
gave higher ratings and made more favorable personnel decisions than those who were in a bad mood (Baron, 1987). One possible explanation is that interviewers in a good mood are more likely to recall the positive performance of the interviewees as it was consistent with their mood. Similarly, those in bad moods are more likely to recall the negative performance of the interviewees. For both types of interviewers, the personnel decisions are complex and the judges want to make accurate choices.

In sum, affect is less likely to influence judgments when direct access or motivated processing strategies are adopted. Affect is more likely to influence judgments when heuristic or substantive processing strategies are used. Therefore, the key is to understand the contextual factors that will determine which judgmental strategy is adopted, so that the extent of the influence of affect can be predicted. According to the AIM, there are three types of contextual factors, including target features, judge features, and situational features that may influence the adoption of judgmental strategies. Target features were not considered in the current study because of our focus on organizational justice. All employees within the same organization, experience the same events and so there is little variance in terms of target features.

As for judge features, PR is of particular importance in the context of organizational justice. By PR, we mean the extent to which a person relates to and is involved in an event. In organizations, particular fairness events may be more personally relevant to some employees. For example, they might be personally involved in the events because the procedures are discriminating against them, or because they have been insulted verbally by their supervisors. These personal experiences lead to high PR that compels the employee to intensely but carefully process information. According to AIM, high PR facilitates the substantive processing strategy, which allows the affect infusion to take place. In contrast, low PR facilitates individuals to adopt loose and simple processing strategies that inhibit affect infusion. In other words, affect is more likely to intrude into the judgmental process and the final judgment if PR is high. Empirical evidence has shown that even very simple manipulations of PR result in quite profound changes in processing strategies (Brewer, 1988; Forgas, 1991; Forgas \& Fiedler, 1996).

Therefore, we argue that in the context of high PR, both positive and negative affect are more likely to infuse into individuals' justice perceptions. We hypothesize that:

Hypothesis 3: Individuals' justice perceptions (distributive justice, procedural justice, interpersonal justice, and informational justice perceptions) will be more influenced by positive affect and negative affect in high PR conditions than in low PR conditions.

Among situational features, group versus individual context may be the most common and the most relevant for organizational justice. We argue that in a group setting there is a positive polarization effect and negative inhibition effect. In a group context, where social desirability is more salient than individual context, the influence of positive affective states will be enhanced, while the influence of negative affective states will be weakened. This is because social and cultural norms generally constrain negative affect, which is associated with stress and a negative experience of events (Gross, John, \& Richards, 2000), so in a group setting negative affect and its influence on subsequent judgment will be reduced. In a group context, the social and cultural norms are especially salient and individuals are more likely to be aware of their negative affect. Such awareness leads individuals to adopt more controlled processing strategies like motivated strategy which will inhibit the affect infusion (Forgas, 1995).

In contrast, positive affect is broadly accepted and desirable in groups and organizations. According to Schachter's (1959) affiliation model, social support can lead to a polarization of emotions, by reducing emotional uncertainty and validating a social hypothesis. When group members support each other's positive affect, it will be enhanced and the influence of the positive affect will be strengthened. Therefore, we hypothesize that:

Hypothesis 4: Group context moderates the relationship between affect and justice perceptions, so that the relationships between positive affect and justice perceptions (distributive justice, procedural 
justice, interpersonal justice, and informational justice perceptions) will be stronger than under individual context and the relationships between negative affect and justice perceptions (distributive justice, procedural justice, interpersonal justice, and informational justice perceptions) will be weaker than under individual context.

\section{STUDY 1}

\section{Sample description}

In total, 140 undergraduate students from an university in Hong Kong volunteered to participate in the experiment. The whole sample was composed of 79 female students $(56.835 \%)$ and 60 male students $(43.165 \%)$ and one missing value. Their ages range from 18 to 24 .

\section{Experimental design}

In this two (positive/negative affect) $\times$ two (group/individual) mixed experimental design, the manipulation of affect was between subject and each participant received either positive or negative affect manipulation; the group/individual manipulation was within subject so that all participants rated justice perceptions individually followed by a group discussion. Once they reached a group consensus on the items, this consensus score was assigned to each group member as their score in the group condition.

In the positive affect condition, students were greeted and were asked to follow the researcher's instructions for filling out a questionnaire. Schwarz and Clore's (1983) procedures for positive affect manipulation were used. The experimenter instructed the participants in the following half a minute, please close your eyes and think about a happy event that happened recently, which makes you happy even when you think of it now. It can be happened in school, family, or your personal life.' After the participants recalled such an event, they were asked to answer the following four questions (Schwarz \& Clore, 1983): 'please describe this event which makes you feel very happy,' 'please describe your feelings when this event happened,' 'please describe what aspects made you feel so,' and 'please describe what such an event made you think about.' After this session, the participants were asked to complete the remaining parts of the questionnaire by themselves, including Positive and Negative Affect Schedule (PANAS), manipulation checks, distributive justice, procedural justice, interpersonal justice, informational justice, PR, positive affectivity, negative affectivity, and demographic information. After this, they were asked to form groups with two or three classmates. Each group was then given a group discussion sheet with the same measurements on justice perceptions. The group members thoroughly discussed the four justice dimensions until they reached a group consensus.

The procedures for the negative affect condition were the same as for the positive affect condition, except that the participants were asked to recall a recent event which made them very unhappy and the follow-up four questions were adjusted accordingly.

\section{Measurements}

\section{Manipulation checks}

Two items were used for affect manipulation check, 'at this moment, I feel very happy' and 'I feel very good right now' (Schwarz \& Clore, 1983).

\section{PANAS}

To provide further support for the manipulation check we assessed positive and negative affective states with 20 adjectival affect descriptors from the PANAS (Watson, Clark, \& Tellegen, 1988). The 10 
adjective descriptors from the positive scale were 'interested,' 'enthusiastic,' 'excited,' 'strong,' 'proud,' 'alert,' 'inspired,' 'attentive,' 'active,' and 'determined.' The 10 adjectives from the negative scale were 'upset,' 'irritable,' 'distressed,' 'guilty,' 'scared,' 'ashamed,' 'nervous,' 'jittery,' 'afraid,' and 'hostile.' Participants were asked to indicate the extent to which they experienced each of the feelings at the time they were completing the survey $(1=$ 'slightly or not at all,' to $5=$ 'very much'). The Cronbach's $\alpha$ was 0.871 for positive affect and 0.852 for negative affect.

\section{Distributive justice}

A 3-item scale adapted from Colquitt (2001) was used and adjusted to measure perceived distributive justice. Students were asked to rate the perceived fairness of their academic results (measured using grade point average). A sample question was 'my GPA reflects the effort I have put into my study' ( $1=$ 'strongly disagree,' to $7=$ 'strongly agree'). The item removed from the original scale was 'my outcome reflects what I have contributed to the organization,' as this item is not suitable for the university context. The Cronbach's $\alpha$ was 0.717 for the individual measure and 0.740 for the group measure.

\section{Procedural justice}

A 7-item scale developed by Colquitt (2001) was used to measure perceived procedural justice ( $1=$ 'strongly disagree,' to $7=$ 'strongly agree'). The items were adjusted to measure whether the procedures in the university were fair or not. A sample question was 'formal procedures of the university hear the concerns of all those affected by the decision.' The Cronbach's $\alpha$ was 0.711 for the individual measure and 0.796 for the group measure.

\section{Interpersonal justice}

A 4-item scale developed by Colquitt (2001) was adjusted and used to measure perceived interactional justice $(1=$ 'strongly disagree,' to $7=$ 'strongly agree'). The target of perceived interpersonal justice was the instructor of the course. One sample question was 'my instructor has treated me with respect.' The Cronbach's $\alpha$ was 0.820 for the individual measure and 0.761 for the group measure.

\section{Informational justice}

We adopted a 5-item scale by Colquitt (2001) to measure perceived interactional justice (1 = 'strongly disagree,' to 7 = 'strongly agree'). Students were asked to rate the perceived informational justice of their course instructor. One sample question was 'the instructor has been candid in his/her communications with me.' The Cronbach's $\alpha$ was 0.763 for the individual measure and 0.683 for the group measure.

\section{$P R$}

Two items were used to measure PR (Forgas, 1995) for each of the three types of justice ( 1 = 'strongly disagree,' to 7 = 'strongly agree'), 'distributive/procedural justice/interactional justice is very important to me' and 'without distributive/procedural justice/interactional justice, I will be very affected.' The Cronbach's $\alpha$ sere $0.817,0.763,0.638$, respectively.

\section{Positive affectivity}

A 3-item scale developed by Iverson, Olekalns, and Erwin (1998) was used to measure positive affectivity. These three items were 'for me, life is a great adventure,' 'I live a very interesting life,' and 'I usually find ways to liven up my day.' The Cronbach's $\alpha$ was 0.771 .

\section{Negative affectivity}

Another three items were employed to evaluate the negative affectivity of the participants (Iverson, Olekalns, \& Erwin, 1998), including 'minor setbacks sometimes irritate me too much,' 'often I get 
irritated at little annoyances,' and 'there are days when I'm 'on edge' all the time.' The Cronbach's $\alpha$ was 0.592 .

\section{Demographics}

Information was collected concerning participants' gender, age, major, and grade.

All translations were conducted followed by the procedures of Brislin (1980). Specifically speaking, we asked two PhD students in management who are fluent in both languages, to translate the original scales from English to Chinese. Two assistant professors in management who are also fluent in both languages are asked to translate these scales back into English. Then we compared these two versions make sure that the keywords in the original scales appear in the final back-translation version, satisfactorily fulfilling the requirements of back-translation.

\section{Analytical strategies}

We first employed structural equation modeling to test the factor structure of the six latent variables under study: distributive justice, procedural justice, interpersonal justice, informational justice, positive affectivity, and negative affectivity. LISREL 8.54 was used to conduct the confirmatory factor analysis. Overall, model fit was examined using various fit indices including the root mean square error of approximation (RMSEA), the incremental fit index, the Tucker-Lewis non-normed index, and the comparative fit index. The requirements of a good model fit were met if RMSEA was below 0.080 (Browne \& Cudeck, 1993) and incremental fit index, Tucker-Lewis non-normed index, and comparative fit index were above 0.900 (Tucker \& Lewis, 1973; Bentler \& Bonett, 1980; Byrne, 1998). The analysis of variance (ANOVA) test was then used to conduct a manipulation check and test the main effect. We employed hieratical regression to test the hypothesized moderation effects later, following procedures by Aiken and West (1991). Hypothesis 4, with mixed design variable, was tested using a general linear model with repeated measures.

\section{Results}

\section{Correlations}

Table 1 presents the descriptive statistics (means and standard deviations) and two types of correlations are reported. Those below the diagonal are the correlations among different variables, and those on the diagonal represent the internal consistency of the variables.

\section{Factor analysis}

Confirmatory factor analysis results showed that our proposed six-factor (four justice types, positive affectivity and negative affectivity) model achieved a good model fit in terms of all fit indices, with $\chi^{2}(910)=1,686.380$, RMSEA of 0.080 , incremental fit index of 0.921 , comparative fit index of 0.910 , and Tucker-Lewis non-normed index of 0.914. We then performed the Harman's one-factor test by loading all the items to one factor, resulting in a poor model fit with $\chi^{2}(991)=1,748.931$, RMSEA of 0.124 , incremental fit index of 0.762 , comparative fit index of 0.750 , and Tucker-Lewis non-normed index of 0.741 , which showed that the respondents could clearly distinguish the six constructs.

\section{Manipulation checks}

The ANOVA test showed that the experimental manipulation (positive/negative affect) resulted in significant differences in the two items of manipulation checks: 'at this moment, I feel very happy' with $F(1,138)=24.052, p<.01$, and 'I feel very good right now' with $F(1,138)=11.931, p<.01$. Participants in a positive affect condition felt happier $(M=4.571)$ than participants in a negative condition 
Table 1. Descriptive statistics and Pearson's correlations - Study 1

\begin{tabular}{|c|c|c|c|c|c|c|c|c|c|c|c|c|c|c|c|}
\hline Variables & Mean & $S D$ & 1 & 2 & 3 & 4 & 5 & 6 & 7 & 8 & 9 & 10 & 11 & 12 & 13 \\
\hline 1. Distributive justice & 3.864 & 1.052 & 0.717 & & & & & & & & & & & & \\
\hline 2. Procedural justice & 3.665 & 0.758 & $0.345^{\star}$ & 0.711 & & & & & & & & & & & \\
\hline 3. Interpersonal justice & 5.311 & 0.725 & 0.085 & 0.011 & 0.820 & & & & & & & & & & \\
\hline 4. Informational justice & 5.049 & 0.658 & $0.257^{\star}$ & $0.160 \dagger$ & $0.661^{\star *}$ & 0.763 & & & & & & & & & \\
\hline 5. Positive affectivity & 2.838 & 0.660 & 0.074 & $0.146 \dagger$ & $0.255^{\star}$ & $0.145 \dagger$ & 0.771 & & & & & & & & \\
\hline 6. Negative affectivity & 2.379 & 0.681 & -0.054 & $-0.194^{\star}$ & -0.108 & -0.131 & $-0.289^{\star \star *}$ & 0.592 & & & & & & & \\
\hline 7. PR of distributive justice & 5.821 & 0.952 & -0.041 & 0.122 & 0.085 & $0.106 \dagger$ & 0.114 & -0.048 & 0.817 & & & & & & \\
\hline 8. PR of procedural justice & 5.176 & 0.942 & 0.019 & -0.018 & 0.106 & $0.159 \dagger$ & 0.101 & $0.167^{\star}$ & $0.418^{\star \star}$ & 0.763 & & & & & \\
\hline 9. PR of interactional justice & 5.150 & 0.907 & -0.001 & 0.051 & $0.395^{\star \star}$ & $0.416^{\star *}$ & $0.181^{*}$ & 0.020 & $0.375^{\star \star}$ & $0.441^{\star *}$ & 0.638 & & & & \\
\hline 10. Group distributive justice & 3.966 & 1.114 & $0.339 * \star$ & $0.217^{\star}$ & 0.005 & $0.208^{\star}$ & $0.183^{\star}$ & -0.014 & 0.021 & $0.156 \dagger$ & 0.027 & 0.740 & & & \\
\hline 11. Group procedural justice & 3.662 & 0.539 & $0.153 \dagger$ & $0.395^{\star \star}$ & -0.032 & 0.080 & 0.020 & -0.090 & -0.001 & 0.094 & -0.007 & $0.431^{\star \star}$ & 0.796 & & \\
\hline 12. Group interpersonal justice & 5.545 & 0.541 & -0.054 & -0.134 & $0.203^{*}$ & 0.101 & $-0.262^{\star}$ & 0.059 & 0.091 & 0.003 & 0.126 & -0.137 & 0.005 & 0.761 & \\
\hline 13. Group informational justice & 5.230 & 0.524 & 0.014 & -0.136 & 0.084 & $0.209^{*}$ & -0.133 & 0.123 & 0.016 & 0.037 & 0.071 & $0.237^{\star}$ & $0.151 \dagger$ & $0.488^{\star \star}$ & 0.683 \\
\hline
\end{tabular}

$\dagger p<.10 ;{ }^{*} p<.05 ;{ }^{\star \star} p<.01 ;$ two-tailed tests.

$\mathrm{PR}=$ personal relevance. 
$(M=3.429)$ and reported feeling better $(M=4.300)$ than in negative condition $(M=3.543)$. Further evidence came from the results of PANAS, which showed significant differences between positive affective states $(F(1,138)=26.804, p<.01)$, and negative affective states $(F(1,138)=14.193, p<.01)$, indicating that the mood manipulation was effective in inducing significantly different affective states in participants.

\section{Hypotheses testing}

Hypotheses 1 and 2 proposed that positive affect was positively related to justice perceptions, while negative affect was negatively related to justice perceptions. The ANOVA test results showed there were significant differences, in the predicted directions, in both procedural justice perceptions $(F(1,138)=16.428$, $p<.01)$, and distributive justice perceptions $(F(1,138)=7.354, p<.01)$. Specifically, participants expressed higher procedural justice perceptions when in a positive $\operatorname{mood}(M=3.910)$ than in a negative $\operatorname{mood}(M=3.416)$; they also expressed higher distributive justice perceptions when in a positive mood $(M=4.100)$ than in a negative $\operatorname{mood}(M=3.629)$. The results were not significant for interpersonal justice perceptions or informational justice perceptions. Thus Hypotheses 1 and 2 were partially supported.

Moderation effect testing. Hypotheses 3 and 4 proposed that PR and group context would both have moderating effects on the relationship between affect and justice perceptions. Hierarchical regression and general linear model (repeated measure) were used to test these two hypotheses, and the results are shown in Tables 2 and 3 .

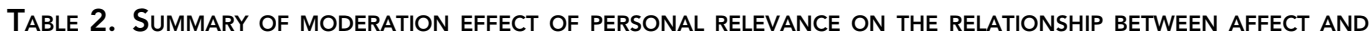
JUSTICE PERCEPTIONS - STUDY 1

\begin{tabular}{|c|c|c|c|c|c|c|c|c|}
\hline \multirow[b]{2}{*}{ Variables } & \multicolumn{2}{|c|}{$\underline{\text { Distributive justice }}$} & \multicolumn{2}{|c|}{ Procedural justice } & \multicolumn{2}{|c|}{ Interpersonal justice } & \multicolumn{2}{|c|}{ Informational justice } \\
\hline & $B$ & SE & $B$ & SE & $B$ & SE & $B$ & SE \\
\hline \multicolumn{9}{|l|}{ Step 1} \\
\hline Positive affectivity & 0.061 & 0.144 & 0.053 & 0.103 & 0.289 ** & 0.096 & $0.359 * \star$ & 0.085 \\
\hline Negative affectivity & 0.048 & 0.139 & -0.026 & 0.099 & -0.003 & 0.092 & -0.069 & 0.082 \\
\hline Gender & 0.073 & 0.188 & $-0.316^{\star}$ & 0.134 & -0.059 & 0.125 & -0.036 & 0.111 \\
\hline Age & -0.121 & 0.098 & -0.014 & 0.070 & -0.093 & 0.065 & -0.043 & 0.058 \\
\hline$\Delta R^{2}$ & \multicolumn{2}{|c|}{0.013} & \multicolumn{2}{|c|}{0.047} & \multicolumn{2}{|c|}{$0.079 *$} & \multicolumn{2}{|c|}{$0.132^{\star \star}$} \\
\hline \multicolumn{9}{|l|}{ Step 2} \\
\hline Positive affectivity & 0.052 & 0.142 & 0.040 & 0.098 & $0.2195^{\star}$ & 0.090 & $0.277^{\star \star}$ & 0.080 \\
\hline Negative affectivity & 0.005 & 0.137 & -0.073 & 0.095 & -0.044 & 0.086 & -0.104 & 0.076 \\
\hline Gender & 0.082 & 0.187 & $-0.302^{\star}$ & 0.128 & 0.024 & 0.117 & 0.037 & 0.103 \\
\hline Age & -0.090 & 0.097 & 0.019 & 0.067 & -0.087 & 0.061 & -0.037 & 0.054 \\
\hline Affect & $0.466^{*}$ & 0.182 & 0.499 & 0.134 & 0.151 & 0.113 & 0.134 & 0.101 \\
\hline Personal relevance & -0.032 & 0.098 & -0.015 & 0.070 & $0.312^{\star \star}$ & 0.064 & $0.274^{\star \star}$ & 0.057 \\
\hline$\Delta R^{2}$ & \multicolumn{2}{|c|}{$0.048^{\star}$} & \multicolumn{2}{|c|}{$0.104^{\star \star}$} & \multicolumn{2}{|c|}{$0.151 * \star$} & \multicolumn{2}{|c|}{$0.140 * \star$} \\
\hline \multicolumn{9}{|l|}{ Step 3} \\
\hline Positive affectivity & 0.015 & 0.139 & 0.042 & 0.095 & $0.187^{\star}$ & 0.090 & $0.272^{\star \star}$ & 0.080 \\
\hline Negative affectivity & -0.014 & 0.135 & -0.093 & 0.093 & -0.050 & 0.086 & -0.108 & 0.076 \\
\hline Gender & 0.015 & 0.185 & $-0.277^{\star}$ & 0.124 & 0.028 & 0.117 & 0.039 & 0.104 \\
\hline Age & -0.099 & 0.095 & -0.014 & 0.066 & -0.081 & 0.061 & -0.034 & 0.054 \\
\hline Affect & $-2.418^{\star}$ & 1.150 & $-1.552^{\star}$ & 0.684 & 0.966 & 0.691 & 0.575 & 0.615 \\
\hline Personal relevance & $-0.277^{\star}$ & 0.136 & $-0.217^{\star}$ & 0.092 & $0.418^{\star \star}$ & 0.109 & $0.331^{\star \star}$ & 0.1097 \\
\hline Affect $\times$ personal relevance & $0.493^{\star}$ & 0.194 & $0.394^{\star \star}$ & 0.130 & -0.157 & 0.132 & -0.085 & 0.117 \\
\hline$\Delta R^{2}$ & \multicolumn{2}{|c|}{$0.045^{\star}$} & \multicolumn{2}{|c|}{$0.057^{\star}$} & \multicolumn{2}{|c|}{0.008} & \multicolumn{2}{|c|}{0.003} \\
\hline
\end{tabular}

${ }^{\star} p<.05 ;{ }^{\star \star} p<.01$ 
Table 2 summarizes the results of the moderating effect of PR on the relationships between affect and justice perceptions. It shows that the PR of distributive justice moderated the relationship between affect and distributive justice, and that the PR of procedural justice moderated the relationship between affect and procedural justice, in the predicted direction. Furthermore, a higher relevance of distributive/procedural justice was associated with a stronger affect (positive/negative). However, this moderation effect was not significant for interpersonal justice and informational justice. Thus, Hypothesis 3 was partially supported. For a clearer picture of the moderation effect, please see Figures $1 \mathrm{a}$ and $1 \mathrm{~b}$.

Hypothesis 4, which contained a between-subject variable and a within-subject variable, was tested using a general linear model with repeated measures, to partition the total variance. Affect was the between-subject variable and the condition of individual/group discussion (I/G) was the within-participants variable; the interaction of affect with $I / G$ was also a withinparticipants effect (Howell, 2007). The results suggested that this interaction term was significant for procedural justice, interpersonal justice, and informational justice, but not for distributive justice. Thus, Hypothesis 4 was partially supported. Figures 2a-2c display these interactional effects.

For procedural justice $(F(1,130)=9.926, p<.01)$, the contrast in the differences showed that the effect of $\mathrm{I} / \mathrm{G}$ was significant on both levels of affect (positive/negative) $(F(1,130)=10.838$, $p<.01)$. In the negative affect condition, participants perceived higher procedural justice in the group condition $\left(M_{G}=3.608\right)$, than in the individual condition $\left(M_{I}=3.411\right)$; while in the positive affect condition, participants perceived lower procedural justice in the group condition $\left(M_{G}=3.693\right)$ than in the individual condition $\left(M_{I}=3.910\right)$. For interpersonal justice $(F(1,130)=8.322, p<.01)$, the contrast between the differences showed that the effect of $\mathrm{I} / \mathrm{G}$ was not significant in the positive affect condition $(F(1,130)=0.532, p>.1)$, but I/G exerted significant effect in the negative condition; participants rated interpersonal justice higher in the group condition $\left(M_{G}=5.678\right)$, than in the individual condition $\left(M_{I}=5.224\right)$. The result was similar for informational justice $(F(1,130)=3.911, p<.05)$, where the $\mathrm{I} / \mathrm{G}$ exerted a significant effect only in the negative condition and participants perceived higher informational justice in the group condition $\left(M_{G}=5.297\right)$ than in the individual condition $\left(M_{I}=4.976\right)$.

\section{STUDY 2}

\section{Sample description}

Study 2 was a replication and cross-validation of Study 1 using an employee sample. We attempted to enhance the generalizability of the results by using the same experimental design as Study 1 . Data were collected from two organizations, eventually resulting in 221 valid data points. In total, 186 employees were from a large textile manufacturing company in Mainland China. Most of this sample $(82.796 \%)$ were manufacturing employees, $6.989 \%$ of this sample worked as clerical staff, and the rest $(10.215 \%)$ of the participants were team leaders, or technicians. Around $88 \%$ of these employees had a secondary school and high school education, and $8.065 \%$ of them had associate degrees or had entered university. Most of them (80.645\%) were under 35. The second sample was from a public organization in Hong Kong. Of the 35 employees, 74.286\% were female. Nearly half of them (51.429\%) were under 35 and most of them $(62.857 \%)$ had higher education, including a bachelor and master degree. Combined, these two subsamples had 53.394\% female participants and most of them $(78.281 \%)$ were under 35 . In the final sample, $96.380 \%$ of the participants had a high school education or above. 

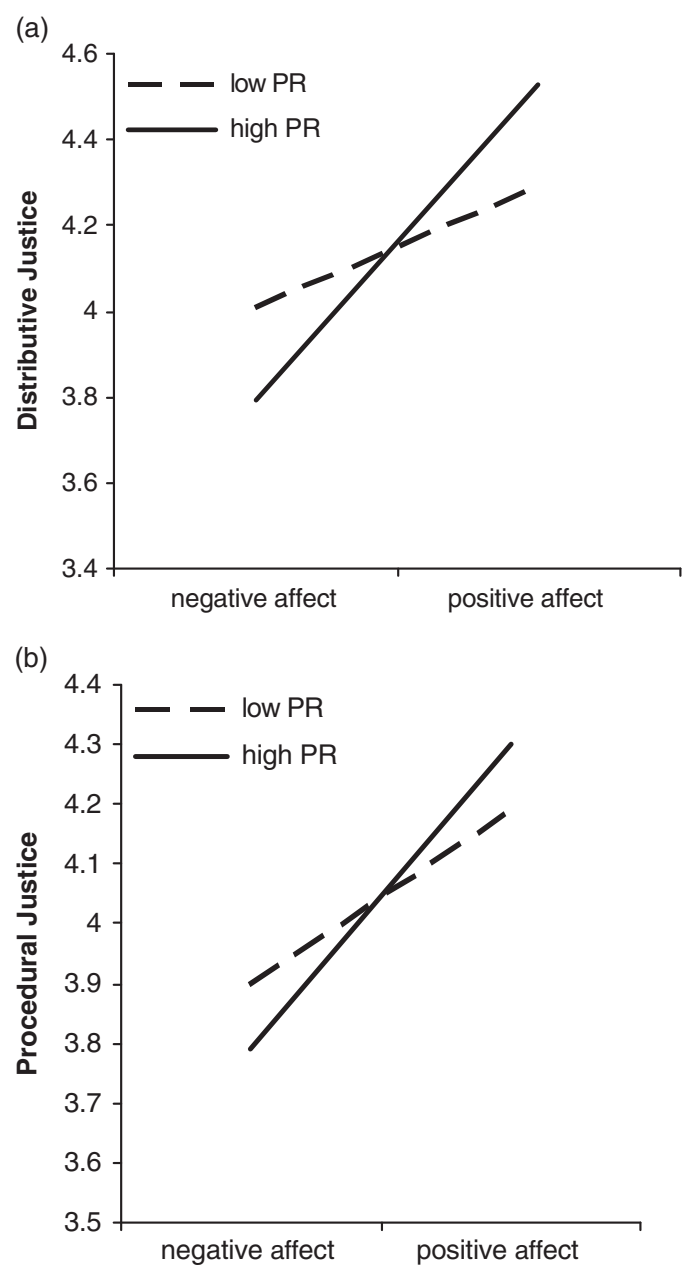

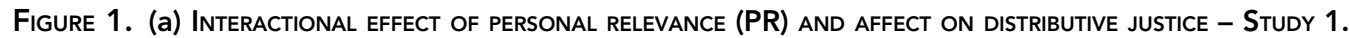
(b) INTERACTIONAL EFFECT OF PERSONAL RELEVANCE AND AFFECT ON PROCEDURAL JUSTICE - StUdY 1

\section{Experimental design, procedures, and manipulation}

We adopted the same experimental design, procedures, and manipulations as in Study 1. In total, 106 of the employees were assigned to the negative affect condition, while 115 were placed in the positive affect condition. The method of manipulation and the procedures were the same as in Study 1.

\section{Measures and analytical strategies}

All the measurements (including manipulation checks, PANAS, distributive justice, procedural justice, interpersonal justice, informational justice, positive affectivity, negative affectivity, PR, and demographical information) were the same as those used in Study 1, with the following exceptions. First, we adjusted the items of justice perceptions so that they fit the organizational context of. Second, all of Colquitt's (2001) four original items were used to measure distributive justice perception, while in Study 1 we dropped one item. Third, we did not measure interactional justice in the group condition, because participants in the same group did not necessarily have the same supervisors, so they 

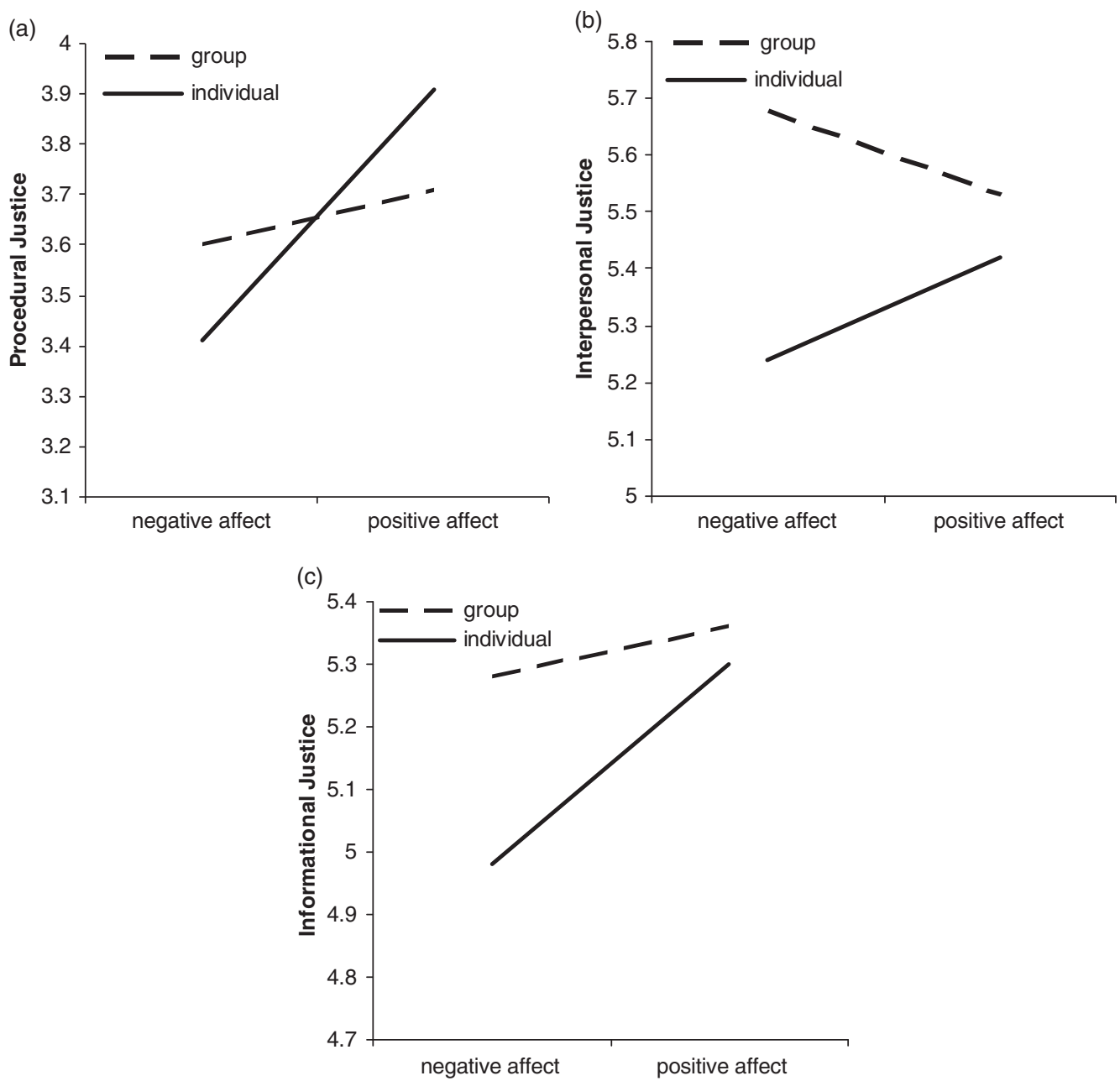

Figure 2. (a) INTERACTIONAL EFFECT OF GROUP CONTEXT AND AFFECT ON PROCEDURAL JUSTICE - STUdY 1.

(b) INTERACTIONAL EFFECT OF GROUP CONTEXT AND AFFECT ON INTERPERSONAL JUSTICE - StUdy 1. (c) INTERACTIONAL EFFECT OF GROUP CONTEXT AND AFFECT ON INFORMATIONAL JUSTICE - STUDY 1

would not have been discussing treatment from the same target. Fourth, two additional control variables were included: organization and education. The analytical strategies were the same as in Study 1.

\section{Results}

\section{Correlations}

Table 3 shows the means, standard deviations, intercorrelations (below the diagonal), and reliabilities (on the diagonal) of the variables.

\section{Factor analysis}

The results showed that the six-factor achieved a model fit with $\chi^{2}(1,133)=3,222.748$, RMSEA of 0.082. Its $\chi^{2} / d f=2.844$, which is acceptable according to Iacobucci (2010). We then performed the 
Harman's one-factor test by loading all items, and the results showed a poor model fit with $\chi^{2}(1,175)=5,091.536$, RMSEA of 0.13 , and $\chi^{2} / d f>3$, suggesting that our proposed six-factor model was more acceptable.

\section{Manipulation checks}

The ANOVA test results showed significant differences in both the manipulation check item 'at this moment, I feel very happy' $(F(1,218)=8.922, p<.01)$, and 'I feel very good right now' $(F(1$, $218)=3.985, p<.05)$. The participants felt happier $(M=5.478)$ and better $(M=5.313)$ in the positive affect condition, than they did in the negative affect condition $(M=4.781 ; M=4.635$, respectively). Therefore, the manipulation of affective states worked in the current study. Further evidence came from the ANOVA test results for the PANAS. The findings showed that participants experienced significantly more $(F(1,218)=8.922, p<.01)$ positive affect in the positive condition $(M=3.793)$ than in negative condition $(M=3.574)$. In addition, participants experienced significantly $(F(1,218)=3.985, p<.05)$ more negative affect in the negative condition $(M=2.431)$ than in positive condition $(M=2.264)$.

\section{Hypotheses testing}

In Hypotheses 1 and 2, two main effects were proposed: (1) positive affect should be associated with higher justice perceptions in all types of justice, including distributive justice, procedural justice, interpersonal justice, and informational justice, and (2) negative affect should be associated with lower justice perceptions. The ANOVA test suggested that Hypotheses 1 and 2 were supported, with significant results with regards to distributive justice $(F(1,218)=12.028, p<.01)$, procedural justice $(F(1,218)=6.206, p<.05)$, interpersonal justice $(F(1,218)=9.892, p<.01)$, and informational justice $(F(1,218)=5.291, p<.05)$. In particular, participants in the positive condition perceived higher distributive justice $(M=4.946)$, procedural justice $(M=4.681)$, interpersonal justice $(M=5.191)$, and informational justice $(M=5.099)$ than those in the negative condition ( $M=4.377, M=4.376, M=4.686, M=4.787$, respectively).

Moderation effect testing. Hypothesis 3 proposed that PR moderated the relationships between affect and all four types of justice perceptions. Hierarchical regression was used to test this hypothesis. The results shown in Table 4 demonstrate that PR significantly moderated the relationships between affect and distributive justice $(\beta=0.177, p<.10)$ and procedural justice $(\beta=0.315, p<.01)$, in the predicted direction. However, this interactional term was not significant for the relationship between affect and interpersonal justice $(\beta=-0.010, p>.10)$ and informational justice $(\beta=0.045, p>.10)$, thus supporting Hypothesis 3 partially. Figures $3 \mathrm{a}$ and $3 \mathrm{~b}$ display the moderation effect of PR on distributive justice and procedural justice.

Hypothesis 4 argued that there would be a positive polarization and negative inhibition effect for distributive justice and procedural justice in the group context. This analysis involved a betweenparticipant variable (positive/negative affect) and a within-subject variable (individual/group). A general linear model-repeated measure was therefore used to test this hypothesis. Results showed that this interactional term was not significant for distributive justice $(F(1,172)=0.306, p>.10)$, but was significant for procedural justice $(F(1,172)=5.451, p<.05)$. In the positive affect condition, the procedural justice perception was lower in the group context $\left(M_{G}=4.460\right)$ than in the individual context $\left(M_{I}=4.681\right)$; in the negative condition, the procedural justice perception was higher in the group context $\left(M_{G}=4.420\right)$ than in the individual context $\left(M_{I}=4.376\right)$. Figure 4 illustrates this moderation effect. 
Table 3. Descriptive statistics and Pearson's correlations - Study 2

\begin{tabular}{|c|c|c|c|c|c|c|c|c|c|c|c|c|c|}
\hline Variables & Mean & $S D$ & 1 & 2 & 3 & 4 & 5 & 6 & 7 & 8 & 9 & 10 & 11 \\
\hline 1. Distributive justice & 4.674 & 1.249 & 0.812 & & & & & & & & & & \\
\hline 2. Procedural justice & 4.535 & 0.920 & $0.343^{\star \star}$ & 0.636 & & & & & & & & & \\
\hline 3. Interpersonal justice & 4.949 & 1.215 & $0.512^{\star \star}$ & $0.417^{\star \star}$ & 0.815 & & & & & & & & \\
\hline 4. Informational justice & 4.950 & 1.014 & $0.529 * \star$ & $0.521^{\star \star}$ & $0.643^{\star \star}$ & 0.716 & & & & & & & \\
\hline 5. Positive affectivity & 3.885 & 0.716 & $0.225^{\star \star}$ & $0.215^{\star \star}$ & $0.322^{\star \star}$ & $0.313^{\star \star}$ & 0.646 & & & & & & \\
\hline 6. Negative affectivity & 3.021 & 0.792 & -0.038 & -0.038 & -0.023 & -0.094 & -0.062 & 0.701 & & & & & \\
\hline 7. PR of distributive justice & 5.114 & 1.307 & 0.009 & 0.37 & 0.062 & 0.015 & $0.190^{\star \star}$ & 0.084 & 0.665 & & & & \\
\hline 8. PR of procedural justice & 5.134 & 1.123 & $0.125 \dagger$ & 0.063 & $0.131 \dagger$ & 0.071 & $0.176^{\star \star}$ & 0.065 & $0.456^{\star \star}$ & 0.509 & & & \\
\hline 9. PR of interactional justice & 5.128 & 1.259 & 0.082 & 0.002 & $0.141^{\star}$ & $0.159 *$ & $0.141^{\star}$ & 0.025 & $0.440 \star \star$ & $0.461^{\star \star}$ & 0.561 & & \\
\hline 10. Group distributive justice & 4.140 & 1.276 & $0.338^{\star \star}$ & $0.184^{\star \star}$ & $0.201^{\star \star}$ & $0.161^{\star}$ & 0.022 & -0.060 & -0.067 & 0.100 & 0.068 & 0.884 & \\
\hline 11. Group procedural justice & 4.441 & 0.870 & 0.086 & $0.257^{\star \star}$ & $0.113+$ & 0.106 & 0.082 & 0.054 & -0.034 & 0.099 & -0.019 & $0.463^{\star \star}$ & 0.730 \\
\hline
\end{tabular}

$\dagger p<.10 ;{ }^{\star} p<.05 ;{ }^{\star *} p<.01 ;$ two-tailed tests.

$\mathrm{PR}=$ personal relevance. 
Table 4. Summary of moderation effect of personal Relevance on the Relationship between affect and JUSTICE PERCEPTIONS - STUDY 2

\begin{tabular}{|c|c|c|c|c|c|c|c|c|}
\hline \multirow[b]{2}{*}{ Variables } & \multicolumn{2}{|c|}{ Distributive justice } & \multicolumn{2}{|c|}{ Procedural justice } & \multicolumn{2}{|c|}{ Interpersonal justice } & \multicolumn{2}{|c|}{ Informational justice } \\
\hline & $B$ & SE & $B$ & SE & $B$ & $S E$ & $B$ & SE \\
\hline \multicolumn{9}{|l|}{ Step 1} \\
\hline Positive affectivity & $0.458^{\star \star}$ & 0.128 & $0.310^{\star \star}$ & 0.093 & $0.572^{\star \star}$ & 0.122 & $0.429 * \star$ & 0.099 \\
\hline Negative affectivity & 0.000 & 0.112 & -0.048 & 0.081 & 0.041 & 0.106 & -0.076 & 0.086 \\
\hline Gender & $0.307 \dagger$ & 0.185 & $0.266^{\star}$ & 0.134 & 0.412 & 0.176 & $0.374^{\star \star}$ & 0.143 \\
\hline Age & 0.007 & 0.012 & 0.005 & 0.009 & $.020 \dagger$ & 0.012 & 0.002 & 0.009 \\
\hline Education & -0.116 & 0.103 & -0.062 & 0.074 & 0.100 & 0.098 & -0.011 & 0.079 \\
\hline Organization & 0.459 & 0.388 & $-0.628^{\star}$ & 0.281 & 0.161 & 0.370 & -0.062 & 0.300 \\
\hline$\Delta R^{2}$ & \multicolumn{2}{|c|}{$0.090^{*}$} & \multicolumn{2}{|c|}{$0.139^{\star \star}$} & \multicolumn{2}{|c|}{$0.178^{\star \star}$} & \multicolumn{2}{|c|}{ 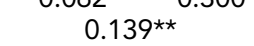 } \\
\hline \multicolumn{9}{|l|}{ Step 2} \\
\hline Positive affectivity & $0.477^{\star \star \star}$ & 0.128 & $0.293^{\star \star}$ & 0.094 & $0.564^{\star \star}$ & 0.122 & $0.396^{* *}$ & 0.099 \\
\hline Negative affectivity & -0.031 & 0.109 & -0.077 & 0.081 & 0.007 & 0.105 & -0.107 & 0.086 \\
\hline Gender & 0.060 & 0.198 & 0.093 & 0.146 & 0.193 & 0.191 & 0.204 & 0.155 \\
\hline Age & 0.009 & 0.012 & 0.006 & 0.009 & $0.021 \dagger$ & 0.012 & 0.000 & 0.009 \\
\hline Education & -0.111 & 0.100 & -0.062 & 0.073 & 0.102 & 0.096 & -0.021 & 0.079 \\
\hline Organization & 0.279 & 0.380 & $-0.0729 \star \star$ & 0.0279 & 0.033 & 0.367 & -0.184 & 0.299 \\
\hline Affect & $0.642^{\star \star}$ & 0.193 & 0.403 & 0.142 & $0.548^{\star *}$ & 0.188 & $0.333^{*}$ & 0.153 \\
\hline Personal relevance & -0.081 & 0.068 & 0.015 & 0.059 & -0.023 & 0.072 & 0.075 & 0.058 \\
\hline$\Delta R^{2}$ & \multicolumn{2}{|c|}{$0.062^{\star}$} & \multicolumn{2}{|c|}{$0.039^{*}$} & \multicolumn{2}{|c|}{$0.039 *$} & \multicolumn{2}{|c|}{$0.035^{\star}$} \\
\hline \multicolumn{9}{|l|}{ Step 3} \\
\hline Positive affectivity & $0.467 * \star$ & 0.128 & $0.256^{\star \star}$ & 0.093 & $0.564^{\star \star}$ & 0.122 & 0.396 ** & 0.099 \\
\hline Negative affectivity & -0.030 & 0.109 & -0.066 & 0.079 & 0.006 & 0.106 & -0.103 & 0.087 \\
\hline Gender & 0.066 & 0.197 & 0.095 & 0.143 & 0.192 & 0.192 & 0.208 & 0.156 \\
\hline Age & 0.010 & 0.012 & 0.008 & 0.009 & $0.021 \dagger$ & 0.012 & 0.000 & 0.009 \\
\hline Education & -0.100 & 0.100 & -0.048 & 0.072 & 0.101 & 0.097 & -0.020 & 0.079 \\
\hline Organization & 0.243 & 0.380 & $-0.716^{\star \star}$ & 0.274 & 0.032 & 0.368 & -0.182 & 0.300 \\
\hline Affect & -0.264 & 0.698 & -0.230 & 0.603 & 0.599 & 0.755 & 0.099 & 0.615 \\
\hline Personal relevance & $-0.173 \dagger$ & 0.096 & $-0.144 \dagger$ & 0.081 & -0.019 & 0.095 & 0.055 & 0.077 \\
\hline Affect $\times$ personal relevance & $0.177 \dagger$ & 0.131 & $0.315^{\star \star}$ & 0.113 & -0.010 & 0.142 & 0.045 & 0.115 \\
\hline$\Delta R^{2}$ & \multicolumn{2}{|c|}{$0.009^{*}$} & \multicolumn{2}{|c|}{$0.036^{\star \star}$} & \multicolumn{2}{|c|}{0.000} & \multicolumn{2}{|c|}{0.001} \\
\hline
\end{tabular}

$\dagger p<.10 ;{ }^{*} p<.05 ;{ }^{*} p<.01$

\section{DISCUSSION}

Previous research has contributed to our understanding of the rational and cognitive processes that people use to form justice perceptions, while leaving the other important aspects of this process relatively unstudied. This is the first paper to use the AIM framework to systematically examine the role of affect in the formation of individuals' justice perceptions. The empirical evidence discussed above supports our view that the AIM is suitable for predicting and explaining how, when and why affect influences the process of individuals' justice perception formation. Using the AIM (Forgas, 1995), we demonstrate that in the process of justice perceptions formation, affect plays a predictive role, and that the magnitude of this influence depends on contextual factors.

In the organizational justice research, one of the most fundamental questions is how individuals form their justice perceptions because justice is subjective in the beholders' eyes. There is a debate for a long time between the role of rational cognitive process versus subjective-affective elements in justice perception formation. And in this battle, the rationalist models dominated, which suggested that the 

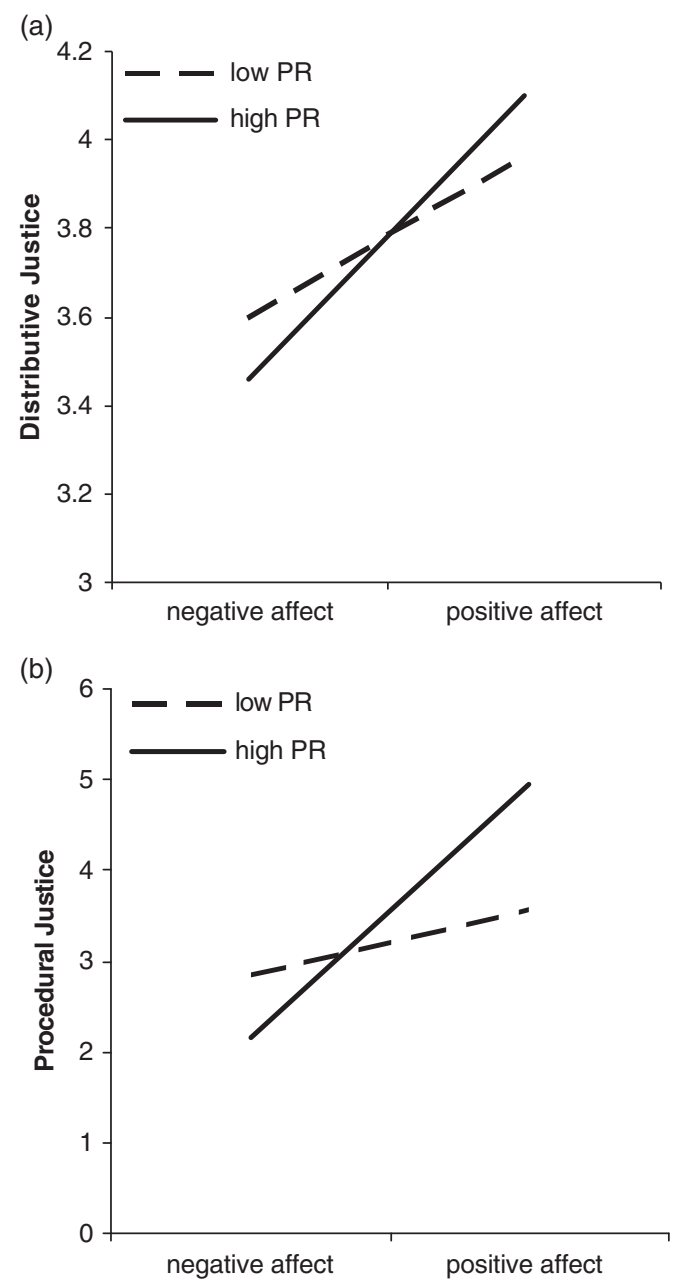

Figure 3. (a) Interactional efFect of Personal ReleVANCE (PR) AND afFect on Distributive Justice - Study 2.

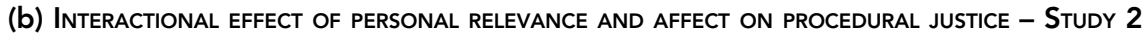

justice perceptions are results of rational reasoning. Under the guidance of this rational approach, affect has been studied as reactions, rather than input, to justice perceptions in justice research. Many researchers have provided insights on the emotions and moods as the results of injustice. For example, Adams (1965) noted that distributive injustice could lead to the experience of anger and guilt. Weiss and Cropanzano (1996) paid attention to how employees experienced in the workplace. They noted that organizational events are proximal causes of affective reactions. In this sense, justice events in organizations can cause employees to experience either happy or unhappy experience, which further influences their job attitudes and affect-driven behaviors. Another comprehensive study by Mikula, Scherer, and Athenstaedt (1998) investigated the relationship between emotions and injustice across 37 countries and found that the following emotions were most associated with injustice, such as anger, disgust, sadness, fear, guilt, and shame.

However, other literature in social cognition noted that intuition will shape our justice judgments. One example of such study is the intuitionist model (Haidt, 2001). According to this model, when people make judgments they do so not by a rationalist reasoning process but rather by a process akin to 


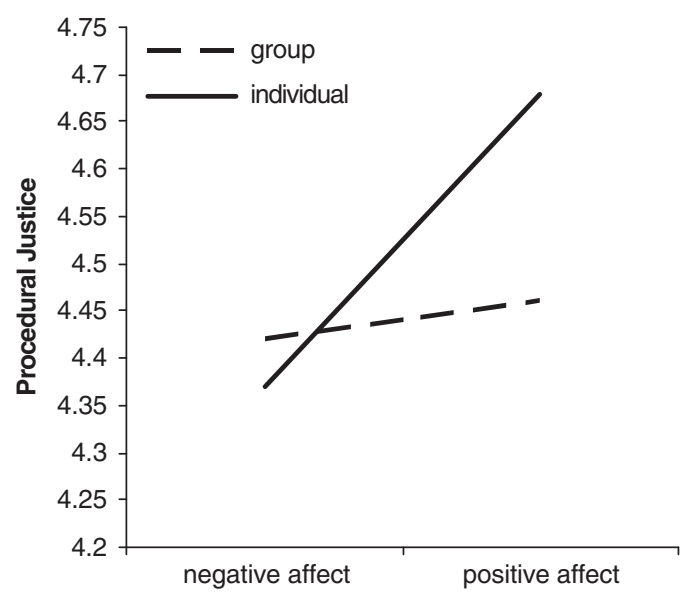

Figure 4. Interactional effect of group context and afFect on procedural Justice - Study 2

intuition (Harrison, 1967). That is, the intuitionist model argues that the intuitions come first and it causes the reasoning to happen. The central claim of the intuitionist model is that 'moral judgment is caused by quick moral intuitions and is followed (when needed) by slow, ex post facto moral reasoning' (Haidt, 2001). For a more vivid metaphor, Haidt (2001) used the 'emotional dog and its rational tail' to describe the relationship between the rationalist model and the intuitionist model. He indicated that when making a moral judgment, one becomes a lawyer trying to build a case rather than a judge searching for the truth. That is, individuals use their quick intuitions to make a judgment first and then try to prove that judgment by rational reasoning. Therefore, the affect issues may be pivotal for a better understanding of organizational justice perceptions formation. This may pave a way for a new area in justice research.

In order to test the hypotheses about the influence of affect on justice perceptions, two experiments were conducted, using a student sample and employee sample simultaneously. The majority of the findings are consistent across these two studies, with minor differences. Both studies confirm the hypothesis that positive affect leads to higher distributive and procedural justice perceptions, and negative affect leads to lower justice perceptions. Furthermore, PR moderates the relationships between affect and distributive and procedural justice. Affect's influence on procedural justice seems to be weaker in a group context than in an individual context. One difference between the studies is that affect's main effect on interpersonal justice and informational justice is not significant for the student sample but is significant for the employee sample.

In terms of the moderation effect of PR, this study shows that when individuals care more about distributive and procedural justice, and perceive these two justice types as highly relevant to them, their perceptions are more strongly influenced by their affect; in other words, compared with individuals who perceive lower PR, their distributive and procedural justice rankings are higher if they are in positive affective states and lower if they are in negative affective states. The AIM predicts that when $\mathrm{PR}$ is high, individuals are more likely to adopt a substantial processing strategy and process information more intensively. In this case, it is more likely that affective information will be processed and incorporated into the judgment, and it will therefore have more influence on the justice perceptions.

Consistent with our prediction, the group context also plays a role in constraining the influence of negative affect on individuals' justice perceptions. When individuals are in negative affect, they are more likely to form lower justice perceptions than those who are not. However, when individuals are in 
a group context and discuss the issue with other group members this influence is reduced. We find this to be true for procedural justice, interpersonal justice, and informational justice perceptions with the student sample, and for procedural justice perception with the employee sample. According to the AIM, when people are subject to public pressure, such as group consent or maintenance of self-image, they are more likely to use a motivated processing strategy and this will reduce the influence of affect. In our study, when people are in a negative mood, but are required to discuss issues with others, it is likely that they are motivated to deflect group pressure and maintain a positive self-image by thinking in a more cognitive and rational way, resulting in the negative inhibition effect as we proposed.

Unexpectedly, the influence of positive affect on procedural justice is also inhibited in the group context for both the student sample and the employee sample. This is not consistent with previous findings on affect polarization in groups (Degoey, 2000). We believe this can be explained by the different cultural norms that shape and justify individual and group beliefs, actions and goals. According to Yik (2010), cultural norms can also influence the regulation of emotional orientation, so that those that do not fit with the cultural values will be discouraged. He suggests that in Eastern societies the self cannot be defined separately from the social context. In addition, harmony with others is an important social belief (Kwan, Hui, \& McGee, 2010). Under these conditions, positive affect can be an expression of one's individuality and uniqueness and could disrupt the harmony of the in-group (Bond, 1996; Wong, Bond, \& Mosquera, 2008). As cultural norms and connectedness to others are especially salient in groups, this could explain why the influence of positive affect is also constrained for procedural justice perceptions in the current study. Future research should consider the effect of different cultural norms on the influence of affect. Distinguishing among different types of positive affect would also be meaningful, as it is possible that positive affective states, such as pride, may have different degrees of social desirability than others, such as joy or enthusiasm.

Another interesting finding is that no moderation effect of group context is found for distributive justice. This might be because distributive justice is more directly connected to the emotional areas of the brain (Dulebohn, Conlon, Sarinopoulos, Davison, \& McNamara, 2009). This strong biological basis between affect and distributive justice is relatively robust and is, therefore, less influenced by such contextual factors as group context. Finally, no significant results were found for interactional justice in terms of the moderation effect of PR. Interactional justice is based on day-to-day encounters. The student study was conducted 1 month into the semester and students may not have had enough opportunities to interact with their instructor. This may also apply to the employee sample; their opportunities to interact with their supervisor on a personal basis are limited, especially for the manufacturing workers. Future research on this issue needs to be more cautious in measuring interactional justice, and to understand the relationships between the two parties. Concerning the inconsistent results found among distributive justice, procedural justice, interpersonal justice, and informational justice, future research could consider whether the conceptualization of overall justice perceptions could facilitate the integrated understanding of the findings of organizational justice or whether it could explain extra variance on top of the specific justice dimensions. Scholars have found that overall justice judgments could mediate the relationship between specific justice judgments and employee attitudes and that trust is a particularly strong predictor of within-person and between-person variance in overall justice perceptions (Ambrose \& Schminke, 2009; Holtz \& Harold, 2009).

In summary, this study takes the next step in the justice field by considering the affective component in the formation of organizational justice perceptions. This is also the first study to systematically apply the AIM to justice perceptions formation, including both the simple main effects and the moderation effects of PR and group context. More research on these issues is needed to advance our understanding of the important role of affect in justice perception formation. Cross-validation is also needed, given 
the contextual dependence of the influence of affect. Finally, the potentially differential effects of various categories of affect would be another interesting field to explore. At present, there is more unknown than known about how affect influences our justice judgments, and we look forward to further work in this fertile field of research.

\section{ACKNOWLEDGEMENTS}

This research was supported by National Natural Science Foundation of China (NNSFC) granted to the first author (Grant number: 71402069). The authors would like to thank the two anonymous reviewers for their very helpful comments and suggestions.

\section{References}

Adams, J. S. (1965). Inequity in social exchange. In L. Berkowitz (Ed.), Advances in experimental social psychology, vol. 2 (pp. 267-299). New York: Academic Press.

Aiken, L. S., \& West, S. G. (1991). Multiple regression: Testing and interpreting interactions. Newbury Park, CA: Sage.

Ambrose, M. L., \& Schminke, M. (2009). The role of overall justice judgments in organizational justice research: A test of mediation. Journal of Applied Psychology, 94, 491-500.

Baron, R. A. (1987). Interviewer's moods and reactions to job applicants: The influence of affective states on applied social judgments. Journal of Applied Social Psychology, 17, 911-926.

Barsade, S. G. (2002). The ripple effect: Emotional contagion and its influence on group behavior. Administrative Science Quarterly, 47, 644-675.

Barsky, A., \& Kaplan, S. A. (2007). If you feel bad, it's unfair: A quantitative synthesis of affect and organizational justice perceptions. Journal of Applied Psychology, 92, 286-295.

Bentler, P. M., \& Bonett, D. G. (1980). Significant tests and goodness of fit in the analysis of covariance structures. Psychological Bulletin, 88, 588-606.

Bies, R. J., \& Moag, J. S. (1986). Interactional justice: Communication criteria of fairness. In B. Sheppard (Ed.), Research on negotiation in organizations, vol. 1 (pp. 43-55). Greenwich: JAI Press.

Bies, R. J., \& Tripp, T. M. (1996). Beyond distrust: ‘Getting even' and the need for revenge. In R. M. Kramer, \& T. R. Tyler (Eds.), Trust in organizations: Frontiers of theory and research (pp. 246-260). Thousand Oaks, CA: Sage.

Bond, M. H. (1996). Handbook of Chinese psychology. Hong Kong: Oxford University Press.

Bower, G. H. (1991). Mood congruity of social judgments. In J. P. Forgas (Ed.), Emotion and social judgments (pp. 31-53). Oxford, England: Pergamon Press.

Brewer, M. B. (1988). A dual process model of impression formation. In R. S. Wyer, \& T. K. Srull (Eds.), Advances in social cognition, vol. 1 (pp. 1-36). Hillsdale, NJ: Erlbaum.

Brief, A. P., \& Weiss, H. M. (2002). Organizational behavior: Affect in the workplace. Annual Review of Psychology, 53, 279-307.

Brislin, R. W. (1980). Translation and content analysis of oral and written materials. In H. C. Triandis, \& J. W. Berry (Eds.), Handbook of cross-cultural psychology, vol. 2: Methodology (pp. 389-444). Boston, MA: Allyn and Bacon.

Browne, M. W., \& Cudeck, R. (1993). Alternative ways of assessing model fit. In K. A. Bollen, \& J. S. Long (Eds.), Testing structural equation models (pp. 445-455). Newbury Park, CA: Sage.

Byrne, B. M. (1998). Structural equation modeling with LISREL, PRELIS, and SIMPLIS: Basic concepts, applications, and programming. Mahwah, NJ: Lawrence Erlbaum Associates.

Chaiken, S. (1987). The heuristic model of persuasion. In M. P. Zanna, J. M. Olson, \& C. P. Herman (Eds.), Social influence: The Ontario symposium (pp. 3-39). Hillsdale, NJ: Erlbaum.

Colquitt, J. A. (2001). On the dimensionality of organizational justice: A construct validation of a measure. Journal of Applied Psychology, 86, 386-400.

Colquitt, J. A., Conlon, D. E., Wesson, M. J., Porter, C. O. L. H., \& Ng, K. Y. (2001). Justice at the millennium: A meta-analytic review of 25 years of organizational justice research. Journal of Applied Psychology, 86, 425-445. 
Daus, C. S. (2001). Rater mood and employee emotional expression in a customer service scenario: interactions and implications for performance review outcomes. Journal of Quality Management, 6, 349-370.

De Cremer, D., \& Van den Bos, K. (2007). Justice and feelings: Toward a new era in justice research. Social Justice Research, 20, 1-9.

Degoey, P. (2000). Contagious justice: Exploring the social construction of justice in organizations. In B. M. Staw, \& R. I. Sutton (Eds.), Research in organizational behavior, vol. 22 (pp. 51-102). New York, NY: JAI.

Deutsch, M. (1975). Equity, equality, and need: What determines which value will be used as the basis of distributive justice? Journal of Social Issues, 31, 137-150.

Diener, E., \& Emmons, R. A. (1985). The independence of positive and negative affect. Journal of Personality and Social Psychology, 47, 1105-1117.

Dulebohn, J. H., Conlon, D. E., Sarinopoulos, I., Davison, R. B., \& McNamara, G. (2009). The biological bases of unfairness: Neuroimaging evidence for the distinctiveness of procedural and distributive justice. Organizational Behavior and Human Decision Processes, 110, 140-151.

Erber, R., \& Erber, M. W. (1994). Beyond mood and social judgment: Mood incongruent recall and mood regulation. European Journal of Social Psychology, 24, 79-88.

Fiedler, K., \& Forgas, J. P. (Eds.) (1988). Affect, cognition and social behavior. Gottingen, Germany: Hogrefe.

Fiske, S. T., \& Taylor, S. E. (1991). Social cognition (2nd ed.). New York: McGraw-Hill.

Folger, R. (1986). A referent cognitions theory of relative deprivation. In J. M. Olson, C. P. Herman, \& M. P. Zanna (Eds.), The Ontario symposium: Relative deprivation and social comparison, vol. 4 (pp. 33-55). Hillsdale, NJ: Lawrence Erlbaum.

Forgas, J. P. (Ed.) (1981). Social cognition: Perspectives on everyday understanding. San Diego, CA: Academic Press.

Forgas, J. P. (Ed.) (1991). Emotion and social judgments. Elmsford, NY: Pergamon Press.

Forgas, J. P. (1992). Affect in social judgments and decisions: A multi-process model. In M. Zanna (Ed.), Advances in experimental social psychology, vol. 25 (pp. 227-275). San Diego, CA: Academic Press.

Forgas, J. P. (1995). Mood and judgment: The affect infusion model (AIM). Psychological Bulletin, 117, 39-66.

Forgas, J. P. (2002). Feeling and doing: Affective influences on interpersonal behavior. Psychological Inquiry, 13, 1-28.

Forgas, J. P., Bower, G. H., \& Krantz, S. (1984). The influence of mood on perceptions of social interactions. Journal of Experimental Social Psychology, 20, 497-513.

Forgas, J. P., \& Moylan, S. J. (1987). After the movies: The effect of transient mood states on social judgments. Personality and Social Psychology Bulletin, 13, 478-489.

Forgas, J. P., \& Bower, G. H. (1987). Mood effects on person perception judgments. Journal of Personality and Social Psychology, 53, 53-60.

Forgas, J. P., \& Fiedler, K. (1996). Us and them: Mood effects on intergroup discrimination. Journal of Personality and Social Psychology, 70, 28-40.

George, J. M., \& Brief, A. P. (1996). Negative affectivity and coping with job loss. Academy of Management Review, 21, 7-9.

Greenberg, J. (1993). The social side of fairness: Interpersonal and informational classes of organizational justice. In R. Cropanzano (Ed.), Justice in the workplace: Approaching fairness in human resource management (pp. 79-103). Hillsdale, NJ: Lawrence Erlbaum Associates.

Gross, J. J., John, O. P., \& Richards, J. M. (2000). The dissociation of emotion expression from emotional experience: A personality perspective. Personality and Social Psychology Bulletin, 26, 712-726.

Haidt, J. (2001). The emotional dog and its rational tail: A social intuitionist approach to moral judgment. Psychological Review, 108, 814-834.

Harrison, J. (1967). Ethical objectivism. In P. Edwards (Ed.), The encyclopedia of philosophy, vols. 3-4 (pp. 71-75). New York: Macmillan.

Holtz, B. C., \& Harold, C. M. (2009). Fair today, fair tomorrow? A longitudinal investigation of overall justice perceptions. Journal of Applied Psychology, 94, 1185-1199.

Hollensbe, E. C., Khazanchi, S., \& Msterson, S. S. (2008). How do I assess if my supervisor and organization are fair? Identifying the rules underlying entity-based justice perceptions. Academy of Management Journal, 51, 1099-1116.

Howell, D. C. (2007). Statistical methods for psychology (6th ed.). Belmont, TN: Thomson Higher Education.

Iacobucci, D. (2010). Structural equations modeling: Fit indices, sample size, and advanced topics. Journal of Consumer Psychology, 20, 90-98. 
Isen, A. M., \& Baron, R. A. (1991). Positive affect as a factor in organizational behavior. In B. M. Stan, \& L. L. Cummings (Eds.), Research in organizational behavior (pp. 132-156). Greenwich, CT: JAI Press.

Iverson, R. D., Olekalns, M., \& Erwin, P. J. (1998). Affectivity, organizational stressors, and absenteeism: A causal model of burnout and its consequences. Journal of Vocational Behavior, 52, 1-23.

Keltner, D., Anderson, C., \& Gonzaga, G. C. (2002). Culture, emotion, and the good life in the study of affect and judgment. Psychological Inquiry, 13, 65-67.

Kwan, V. S. Y., Hui, C.-M., \& McGee, J. A. (2010). What do we know about the Chinese self? Illustrations with selfesteem, self-efficacy, and self-enhancement. In M. H. Bond (Ed.), The Oxford handbook of Chinese psychology (pp. 279-294). New York: Oxford University.

Leventhal, G. S. (1976). The distribution of rewards and resources in groups and organizations. In L. Berkowitz, \& W. Walster (Eds.), Advances in experimental social psychology, vol. 9 (pp. 91-131). New York: Academic Press.

Leventhal, G. S. (1980). What should be done with equity theory? New approaches to the study of fairness in social relationships. In K. Gergen, M. Greenberg, \& R. Willis (Eds.), Social exchange: Advances in theory and research (pp. 27-55). New York: Plenum Press.

Leventhal, G. S., Karuza, J., \& Fry, W. R. (1980). Beyond fairness: A theory of allocation preferences. In G. Mikula (Ed.), Justice and social interaction (pp. 167-218). Stuttgart: Huber.

Mayer, J. D. (1986). How mood influences cognition. In N. E. Sharkey (Ed.), Advances in cognitive science, vol. 1 (pp. 290-314). Chichester, England: Ellis Horwood.

Mikula, G., Scherer, K. R., \& Athenstaedt, U. (1998). The role of injustice in the elicitation of differential emotional reactions. Personality and Social Psychological Bulletin, 24, 769-783.

Mittal, V., \& Ross, W. T., Jr. (1998). The impact of positive and negative affect and issue framing on issue interpretation and risk taking. Organizational Behavior and Human Decision Processes, 76, 298-324.

Pugh, S. D. (2001). Service with a smile: Emotional contagion in the service encounter. Academy of Management Journal, 44, 1018-1027.

Schachter, S. (1959). The psychology of affliation. Stanford, CA: Stanford University Press.

Scher, S. J., \& Heise, D. R. (1993). Affect and the perception of injustice. Advances in Group Process, 10, 223-252.

Schwarz, N., \& Clore, G. L. (1983). Mood, misattribution, and judgments of well-being: Informative and directive functions of affective status. Journal of Personality and Social Psychology, 45, 513-523.

Seo, M., Barrett, L., \& Bartunek, J. M. (2004). The role of affective experience in work motivation. Academy of Management Review, 29, 423-439.

Srull, T. K. (1983). Affect and memory: The impact of affective reactions in advertising on the representation of product information in memory. In R. Bagozzi, \& A. Tybout (Eds.), Advances in consumer research (Vol. 10, pp. 244-263). Ann Arbor, MI: Association for consumer Research.

Srull, T. K. (1984). The effects of subjective affective states on memory and judgment. In T. Kinnear (Ed.), Advances in consumer research (vol. 11, pp. 530-533). Provo, UT: Association for Consumer Research.

Swann, W. B., Jr. (1992). Seeking "truth" and finding despair: Some unhappy consequences of negative self-concept. Current Directions in Psychological Sciences, 1, 15-18.

Tanaka, K., \& Takimoto, S. (1997). Effects of interpersonal affect upon fairness judgment. Japanese Psychological Research, 39, 312-322.

Taylor, S. E. (1991). Asymmetrical effects of positive and negative events: The mobilization-minimization hypothesis. Psychological Bulletin, 110, 67-85.

Thibaut, J., \& Walker, L. (1975). Procedural justice: A psychological analysis. Hillsdale, NJ: Erlbaum.

Tucker, L. R., \& Lewis, C. (1973). The reliability coefficient for maximum likelihood factor analysis. Psychometrika, $38,1-10$.

Van den Bos, K. (2003). On the subjective quality of social justice: The role of affect as information in the psychology of justice judgments. Journal of Personality and Social Psychology, 85, 482-498.

Vaughan, G. M., \& Hogg, M. A. (2005). Introduction to social psychology (4th ed.). French Forest NSW: Prentice Hall, Pearson Education Australia.

Venkatesh, V., \& Speier, C. (1999). Computer technology training in the workplace: A longitudinal investigation of the effect of mood. Organizational Behavior and Human Decision Processes, 79, 1-28.

Watson, D., Clark, A. L., \& Tellegen, A. (1988). Development and validation of brief measures of positive and negative affect: The PANAS scales. Journal of Personality and Social Psychology, 54, 1063-1070. 
Weiss, H. M., \& Cropanzano, R. (1996). Affective events theory: A theoretical discussion of the structure, causes and consequences of affective experiences at work. In B. M. Staw, \& L. L. Cummings (Eds.), Research in Organizational Behavior (vol. 18, pp. 1-74). London: JAI Press Inc.

Wellen, J. M., Hogg, M. A., \& Terry, D. J. (1998). Group Norms and Attitude-Behavior Consistency: The Role of Group Salience and Mood. Group Dynamics, 2, 48-56.

Wong, S., Bond, M. H., \& Mosquera, P. M. R. (2008). The influence of cultural value orientations on self-reported emotional expression across cultures. Journal of Cross-Cultural Psychology, 39, 224-229.

Yik, M. (2010). How unique is Chinese emotion? In M. H. Bond (Ed.), The Oxford handbook of Chinese psychology (pp. 205-220). New York: Oxford University. 